\title{
Prolonged antithrombotic therapy in patients after acute coronary syndrome: A critical appraisal of current European Society of Cardiology guidelines
}

\author{
Jacek Kubica ${ }^{1}$, Piotr Adamski ${ }^{1}$, Piotr Niezgoda ${ }^{1}$, Dimitrios Alexopoulos $^{2}$, \\ Jolita Badarienè ${ }^{3}$, Andrzej Budaj ${ }^{4}$, Katarzyna Buszko ${ }^{5}$, Dariusz Dudek ${ }^{6,7}$,
} Tomasz Fabiszak ${ }^{1}$, Mariusz Gąsior ${ }^{8}$, Robert Gil ${ }^{9}$, Diana A. Gorog ${ }^{10}$, Stefan Grajek ${ }^{11}$, Paul A. Gurbel ${ }^{12}$, Marcin Gruchała ${ }^{13}$, Miłosz J. Jaguszewski ${ }^{13}$, Stefan James ${ }^{14}$, Young-Hoon Jeong ${ }^{15}$, Bernd Jilma ${ }^{16}$, Jarosław D. Kasprzak ${ }^{17}$, Andrzej Kleinrok ${ }^{18,19}$, Aldona Kubica $^{20}$, Wiktor Kuliczkowski ${ }^{21}$, Jacek Legutko ${ }^{22}$, Maciej Lesiak ${ }^{11}$, Jolanta M. Siller-Matula ${ }^{23,24}$, Klaudiusz Nadolny ${ }^{25,26}$, Krzysztof Pstrągowski ${ }^{1}$, Salvatore Di Somma ${ }^{27}$, Giuseppe Specchia ${ }^{28}$, Janina Stępińska ${ }^{29}$, Udaya S. Tantry ${ }^{12}$, Agnieszka Tycińska $^{30}$, Monica Verdoia ${ }^{31}$, Wojciech Wojakowski ${ }^{32}$, Eliano P. Navarese ${ }^{1}$

${ }^{1}$ Department of Cardiology and Internal Medicine, Collegium Medicum, Nicolaus Copernicus University, Bydgoszcz, Poland; ${ }^{2}$ National and Kapodistrian University of Athens Medical School, Attikon University Hospital, Athens, Greece; ${ }^{3} \mathrm{Clinic}$ of Cardiac and Vascular Diseases, Institute of Clinical Medicine, Faculty of Medicine, Vilnius University, Vilnius, Lithuania; ${ }^{4}$ Department of Cardiology, Center of Postgraduate

Medical Education, Grochowski Hospital, Warsaw, Poland; ${ }^{5}$ Department of Theoretical Foundations of Bio-Medical Science and Medical Informatics, Collegium Medicum, Nicolaus Copernicus University, Bydgoszcz, Poland; ${ }^{6}$ Institute of Cardiology, Jagiellonian University Medical College, Krakow, Poland;

${ }^{7}$ Maria Cecilia Hospital, GVM Care and Research, Cotignola (RA), Ravenna, Italy; ${ }^{8} 3^{\text {rd }}$ Department of Cardiology, Silesian Center for Heart Diseases, Faculty of Medicine in Zabrze, Medical University of Silesia, Zabrze, Poland; ' ${ }^{9}$ epartment of Invasive Cardiology, Center of Postgraduate Medical Education,

Central Hospital of the Internal Affairs and Administration Ministry, Warsaw, Poland; ${ }^{10}$ Postgraduate Medicine, University of Hertfordshire, United Kingdom and Faculty of Medicine, National Heart and Lung Institute, Imperial College, London, United Kingdom; ${ }^{11}$ Department of Cardiology, Poznan University of Medical Sciences, Poznan, Poland; ${ }^{12}$ Sinai Center for Thrombosis Research and Drug Development, Sinai

Hospital of Baltimore, MD, USA; ${ }^{13} 1^{\text {st }}$ Department of Cardiology, Medical University of Gdansk, Poland;

${ }^{14}$ Department of Medical Sciences and Uppsala Clinical Research Center, Uppsala University Hospital, Uppsala, Sweden; ${ }^{15}$ Department of Internal Medicine, Gyeongsang National University School of Medicine and Cardiovascular Center, Gyeongsang National University Changwon Hospital, Changwon, South Korea;

${ }^{16}$ Department of Clinical Pharmacology, Medical University of Vienna, Austria; ${ }^{17} 1^{\text {st }}$ Department and Chair of Cardiology, Medical University of Lodz, Bieganski Hospital, Lodz, Poland; ${ }^{18}$ University of Information

Technology and Management in Rzeszow, Poland; ${ }^{19}$ Department of Cardiology, The Pope John Paul II Hospital in Zamosc, Poland; ${ }^{20}$ Department of Health Promotion, Collegium Medicum, Nicolaus Copernicus

University, Bydgoszcz, Poland; ${ }^{21}$ Department of Cardiology, Medical University of Wrocław, Poland; ${ }^{22}$ Department of Interventional Cardiology, Institute of Cardiology, Jagiellonian University Medical College, John Paul II Hospital in Krakow, Poland; ${ }^{23}$ Department of Experimental and Clinical Pharmacology, Medical University of Warsaw, Poland; ${ }^{24}$ Department of Cardiology, Medical University of Vienna, Austria;

${ }^{25}$ Department of Emergency Medical Service, Strategic Planning University of Dabrowa Gornicza, Poland; ${ }^{26}$ Faculty of Medicine, Katowice School of Technology, Katowice, Poland; ${ }^{27}$ Department of Medical-Surgery Sciences and Translational Medicine, University La Sapienza, Rome, Italy; ${ }^{28}$ Pavia, Italy; ${ }^{29}$ Department of Intensive Cardiac Therapy, National Institute of Cardiology, Warsaw, Poland; ${ }^{30}$ Department of Cardiology,

Medical University of Bialystok, Poland; ${ }^{31}$ Division of Cardiology, Ospedale degli Infermi ASL Biella, Università del Piemonte Orientale, Italy; ${ }^{32}$ Division of Cardiology and Structural Heart Diseases, Medical University of Silesia, Katowice, Poland

Address for correspondence: Prof. Jacek Kubica, Department of Cardiology and Internal Medicine, Collegium Medicum, Nicolaus Copernicus University, ul. M. Skłodowskiej-Curie 9, 85-094 Bydgoszcz, Poland, tel: +48 525854023 , fax: +4852 5854024, e-mail: jkubica@cm.umk.pl 
This article has been co-published in the 'Medical Research Journal' 2020, vol. 5, no. 3, pages: 177-190, doi: 10.5603/MRJ.a2020.0035 with permission of both Editorial Boards and the Publisher.

\begin{abstract}
The increased risk of non-cardiovascular death in patients receiving clopidogrel or prasugrel in comparison with the placebo group in the Dual Antiplatelet Therapy (DAPT) trial in contrast to the decreased risk of cardiovascular death and all-cause death seen in patients treated with low-dose ticagrelor in the EU label population of the PEGASUS-TIMI 54 trial, resulted in inclusion in the 2020 ESC NSTE-ACS guidelines the recommendation for use of clopidogrel or prasugrel only if the patient is not eligible for treatment with ticagrelor.

The prevalence of the primary outcome composed of cardiovascular death, stroke, or myocardial infarction was lower in the low-dose rivaroxaban and acetylsalicylic acid (ASA) group than in the ASA-alone group in the COMPASS trial. Moreover, all-cause mortality and cardiovascular mortality rates were lower in the rivaroxaban-plus-ASA group.

Comparison of the PEGASUS-TIMI 54 and COMPASS trial patient characteristics clearly shows that each of these treatment strategies should be addressed at different groups of patients. A greater benefit in post-acute coronary syndrome (ACS) patients with a high risk of ischemic events and without high bleeding risk may be expected with ASA and ticagrelor $60 \mathrm{mg}$ b.i.d. when the therapy is continued without interruption or with short interruption only after ACS. On the other hand, ASA and rivaroxaban $2.5 \mathrm{mg}$ b.i.d. seems to be a better option when indications for dual antithrombotic therapy (DATT) appear after a longer time from ACS (more than 2 years) and/or from cessation of DAPT (more than 1 year) and in patients with multiple vascular bed atherosclerosis. Thus, both options of DATTs complement each other rather than compete, as can be presumed from the recommendations. However, a direct comparison between these strategies should be tested in future clinical trials. (Cardiol J 2020; 27, 6: 661-676)
\end{abstract}

Key words: prolonged antithrombotic therapy, chronic coronary syndrome, acute coronary syndrome, rivaroxaban, ticagrelor, clopidogrel, prasugrel

\section{Introduction}

Conventional antithrombotic therapy following myocardial revascularization in acute coronary syndrome (ACS) patients comprises low-dose acetylsalicylic acid (ASA) and a P2Y12 receptor inhibitor - a combination referred to as dual antiplatelet therapy (DAPT) - for up to 12 months after ACS [1-5]. However, increased risk of ischemic events persists in a substantial proportion of stable patients who have completed this period of DAPT after ACS [6-9].

According to the 2019 European Society of Cardiology (ESC) guidelines for the diagnosis and management of chronic coronary syndromes (CCS), "adding a second antithrombotic drug to ASA for long-term secondary prevention should be considered in patients with a high risk of ischemic events and without high bleeding risk" (class of recommendation IIa, level of evidence A) - as a dual antithrombotic therapy (DATT). This strategy "may be also considered in patients with at least a moderately increased risk of ischemic events and without high bleeding risk" (class of recommendation IIb, level of evidence A) [10].

The same document specifies risk factors defining high and moderate risk of ischemic complications as well as high bleeding risk in patients with CCS, remaining in sinus rhythm (Table 1) [10].

The 2020 ESC guidelines for the management of ACSs in patients presenting without persistent ST-segment elevation modified the ischemic risk assessment (Table 2) and introduced a definition of a high risk of bleeding according to the Academic Research Consortium for High Bleeding Risk (Table 3) [11].

It is also expressed in the guidelines that prolonged antithrombotic therapy with a combination of ASA and either a second antiplatelet agent or rivaroxaban at the "vascular dose" of $2.5 \mathrm{mg}$ b.i.d can be considered an option for patients with increased ischemic risk, who completed the standard 12-month DAPT following myocardial revascularization due to acute myocardial infarction (MI). The pivotal question that arises at this point is: which treatment should be applied to 
Table 1. Risk factors of high/moderate ischemic and high bleeding risk in patients with chronic coronary syndromes in sinus rhythm according to the 2019 ESC CCS guidelines [10].

\begin{tabular}{|c|c|}
\hline High ischemic risk* & High bleeding risk \\
\hline $\begin{array}{l}\text { Diffuse multivessel CAD with at least one } \\
\text { of the following: } \\
\text { - Diabetes mellitus requiring medication } \\
\text { - Recurrent } \mathrm{MI} \\
\text { - PAD } \\
\text { - CKD with eGFR } 15-59 \mathrm{~mL} / \mathrm{min} / 1.73 \mathrm{~m}^{2}\end{array}$ & $\begin{array}{l}\text { - Prior history of intracerebral hemorrhage or ischemic stroke } \\
\text { - History of other intracranial pathology } \\
\text { - Recent gastrointestinal bleeding or anemia due } \\
\text { to possible gastrointestinal blood loss } \\
\text { - Other gastrointestinal pathology associated with } \\
\text { increased bleeding risk } \\
\text { - Liver failure } \\
\text { - Bleeding diathesis or coagulopathy } \\
\text { - Extreme old age or frailty } \\
\text { - Renal failure requiring dialysis or with eGFR }<15 \mathrm{~mL} / \mathrm{min} / 1.73 \mathrm{~m}^{2}\end{array}$ \\
\hline
\end{tabular}

* Moderate risk if any single factor, including HF, is present; CAD — coronary artery disease; CKD — chronic kidney disease; $\mathrm{GFR}$ - estimated glomerular filtration rate; HF - heart failure; $\mathrm{MI}$ - myocardial infarction; PAD - peripheral artery disease

Table 2. Risk factors of ischemic events - criteria for extended treatment with a second antithrombotic agent according to the 2020 ESC NSTE-ACS guidelines [11].

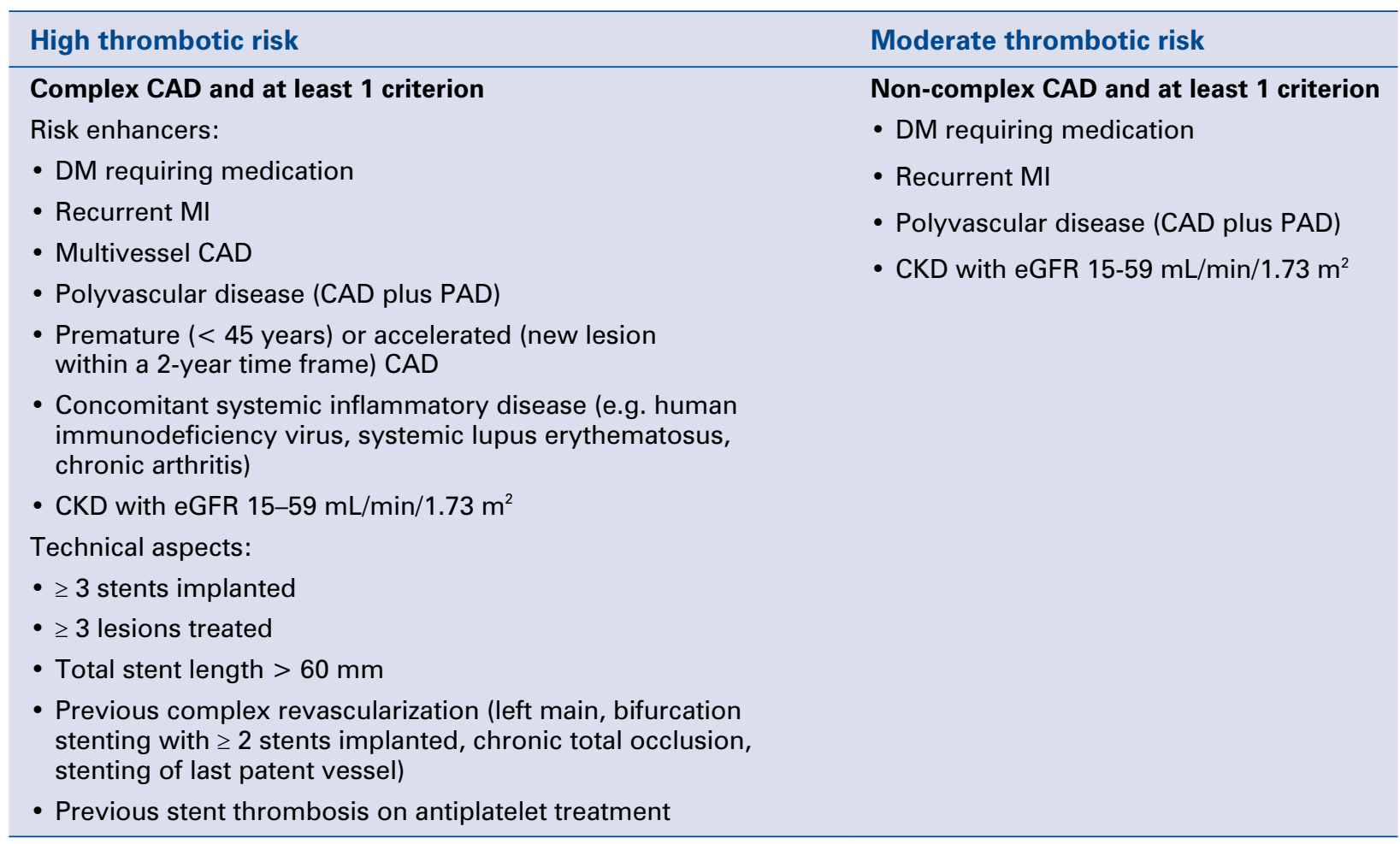

CAD - coronary artery disease; CKD — chronic kidney disease; DM - diabetes mellitus; eGFR - estimated glomerular filtration rate; $\mathrm{MI}$ - myocardial infarction; PAD - peripheral artery disease

which patient? Unfortunately, the indications and cautions mentioned in the guidelines are too vague and too limited to assist practicing physicians in making this choice in the real-world scenario (Table 4) [10,11]. Thus, according to the authors of this position paper, the essential practical implications of these recommendations are still missing. Therefore, while designing the ELECTRA-SIRIO 2 randomized clinical trial, aiming to assess strate- gies of treatment in stable patients after MI, we decided to analyze ESC recommendations as well as available evidence regarding this issue $[12,13]$.

\section{Trials supporting recommendation for DATT in CCS patients after MI}

The ESC recommendations $[10,11]$ are based on several large randomized clinical trials con- 
Table 3. Criteria for high bleeding risk according to the Academic Research Consortium for High Bleeding Risk at the time of percutaneous coronary intervention (bleeding risk is high if at least one major or two minor criteria are met) [11].

\begin{tabular}{ll}
\hline Major & Minor \\
\hline Anticipated use of long-term OAC & Age $\geq 75$ years \\
Severe or end-stage CKD (eGFR $<30 \mathrm{~mL} / \mathrm{min})$ & Moderate CKD (eGFR $30-59 \mathrm{~mL} / \mathrm{min}$ ) \\
Hemoglobin $<11 \mathrm{~g} / \mathrm{dL}$ & $\begin{array}{l}\text { Hemoglobin } 11-12.9 \mathrm{~g} / \mathrm{dL} \text { for men or } \\
\text { 11-11.9 g/dL for women }\end{array}$ \\
$\begin{array}{l}\text { Spontaneous bleeding requiring hospitalization } \\
\text { and/ortransfusion in the past } 6 \text { months or at }\end{array}$ & $\begin{array}{l}\text { Spontaneous bleeding requiring hospitalization } \\
\text { and/or transfusion within the past } 12 \text { months, }\end{array}$ \\
$\begin{array}{l}\text { Baseline thrombocytopenia } \\
\left.\text { (platelet count }<100-10^{9} / \mathrm{L}\right)\end{array}$ & $\begin{array}{l}\text { Chronic use of oral non-steroidal anti-inflammatory } \\
\text { drugs or steroids }\end{array}$ \\
Chronic bleeding diathesis & Ischemic stroke not meeting the major criterion \\
Liver cirrhosis with portal hypertension & \\
Active malignancy (excluding non-melanoma & \\
skin cancer) within the past 12 months & \\
Previous spontaneous intracranial hemorrhage & \\
Previous traumatic intracranial hemorrhage within & \\
the past 12 months & \\
Presence of a brain arteriovenous malformation & \\
Moderate or severe ischemic stroke within the & \\
past 6 months & \\
Recent major surgery or major trauma within & \\
30 days prior to PCl & \\
Non-deferrable major surgery on DAPT & \\
\hline
\end{tabular}

CKD - chronic kidney disease; DAPT — dual antiplatelet therapy; eGFR - estimated glomerular filtration rate; PCI — percutaneous coronary intervention; OAC — oral anticoagulant

Table 4. Treatment options for dual antithrombotic therapy in combination with acetylsalicylic acid (75-100 mg daily) in patients with a high or moderate risk of ischemic events and without high bleeding risk $[10,11]$.

\begin{tabular}{|c|c|c|c|c|}
\hline Drug option & Dose & Indication & $\begin{array}{l}\text { Additional } \\
\text { cautions }\end{array}$ & $\begin{array}{c}\text { Supporting } \\
\text { trial }\end{array}$ \\
\hline Clopidogrel & $75 \mathrm{mg}$ o.d. & $\begin{array}{c}\text { Post-MI in patients } \\
\text { who have tolerated DAPT } \\
\text { for } 1 \text { year }\end{array}$ & & DAPT \\
\hline Prasugrel & $\begin{array}{c}10 \mathrm{mg} \text { o.d. or } \\
5 \mathrm{mg} \text { o.d.; if } \\
\text { body weight } \\
<60 \mathrm{~kg} \text { or age } \\
>75 \text { years }\end{array}$ & $\begin{array}{l}\text { Post-PCI for MI in patients } \\
\text { who have tolerated DAPT } \\
\text { for } 1 \text { year }\end{array}$ & Age $>75$ years & $\begin{array}{c}\text { DAPT } \\
\text { TL-PAS }\end{array}$ \\
\hline Ticagrelor & 60 mg b.i.d. & $\begin{array}{c}\text { Post-Ml in patients } \\
\text { who have tolerated DAPT } \\
\text { for } 1 \text { year }\end{array}$ & & PEGASUS-TIMI 54 \\
\hline \multirow[t]{3}{*}{ Rivaroxaban } & 2.5 mg b.i.d. & $\begin{array}{l}\text { Post-MI > } 1 \text { year or } \\
\text { multivessel CAD [10] }\end{array}$ & $\mathrm{CrCl} 15-29 \mathrm{~mL} / \mathrm{min}$ & COMPASS \\
\hline & & or & & \\
\hline & & $\begin{array}{l}\text { Patients with CAD or } \\
\text { symptomatic PAD at high } \\
\text { risk of ischemic events [11] }\end{array}$ & & \\
\hline
\end{tabular}

$\mathrm{CAD}$ - coronary artery disease; $\mathrm{CrCl}$ — creatinine clearance; DAPT — dual antiplatelet therapy; $\mathrm{MI}$ — myocardial infarction; PAD — peripheral artery disease; $\mathrm{PCl}$ - percutaneous coronary intervention 
Table 5. Clinical trials supporting the 2019 European Society of Cardiology (ESC) guidelines for the diagnosis and management of chronic coronary syndromes (according to citations) [14-22].

\begin{tabular}{|c|c|c|c|c|}
\hline $\begin{array}{l}\text { Study } \\
\text { ClinicalTrials.gov }\end{array}$ & Publication & Patients & Study treatment & Outcome \\
\hline \multirow[t]{2}{*}{$\begin{array}{l}\text { DAPT } \\
\text { NCT00977938 }\end{array}$} & $\begin{array}{c}\text { Mauri et al. } \\
\text { NEJM } 2014 \text { [14] }\end{array}$ & $\begin{array}{l}\mathrm{N}=9961 \mathrm{pts} \\
12 \mathrm{~m} \text { after DES } \\
\text { implantation }\end{array}$ & $\begin{array}{l}\text { clo } 1 \times 75 \mathrm{mg} \text { or } \\
\text { pra } 1 \times 10 \mathrm{mg} \text { or } \\
1 \times 5 \mathrm{mg} \text { in pts who } \\
\text { weighed }<60 \mathrm{~kg} \\
\text { and ASA vs. placebo } \\
\text { and ASA up to } 30 \mathrm{~m}\end{array}$ & $\begin{array}{l}\text { DAPT beyond } 1 \text { year after } \\
\text { DES placement reduced the } \\
\text { risks of ST and MACCE, but } \\
\text { was associated with an in- } \\
\text { creased risk of bleeding }\end{array}$ \\
\hline & $\begin{array}{c}\text { Yeh et al. } \\
\text { JACC } 2015 \text { [15] }\end{array}$ & $\begin{array}{c}\mathrm{N}=11,648 \mathrm{pts} \\
\mathrm{MI}(\mathrm{n}=3576) \\
\text { No-MI }(\mathrm{n}=8072) \\
12 \mathrm{~m} \text { after stent } \\
\text { implantation } \\
\text { DES ( } \mathrm{n}=9961) \\
\text { BMS }(\mathrm{n}=1687)\end{array}$ & $\begin{array}{c}\text { clo } 1 \times 75 \mathrm{mg} \text { or } \\
\text { pra } 1 \times 10 \mathrm{mg} \text { or } \\
1 \times 5 \mathrm{mg} \text { in pts who } \\
\text { weighed }<60 \mathrm{~kg} \\
\text { and ASA vs. placebo } \\
\text { and ASA up to } 30 \mathrm{~m}\end{array}$ & $\begin{array}{l}30 \text { m of DAPT after stent } \\
\text { placement reduced risk of } \\
\text { ST and MI in pts with and } \\
\text { without MI and increased } \\
\text { bleeding }\end{array}$ \\
\hline $\begin{array}{l}\text { DAPT/TL-PAS } \\
\text { NCT00997503 } \\
\text { Sub-population } \\
\text { of the DAPT trial }\end{array}$ & $\begin{array}{c}\text { Garratt et al. } \\
\text { Circulation } 2015 \\
{[16]}\end{array}$ & $\begin{array}{c}\mathrm{N}=2191 \mathrm{pts} \\
12 \mathrm{~m} \text { after TAXUS } \\
\text { implantation }\end{array}$ & $\begin{array}{c}\text { pra } 1 \times 10 \mathrm{mg} \text { or } \\
1 \times 5 \mathrm{mg} \text { in pts who } \\
\text { weighed }<60 \mathrm{~kg} \\
\text { and ASA vs. placebo } \\
\text { and ASA up to } 30 \mathrm{~m}\end{array}$ & $\begin{array}{l}\text { DAPT continued for } 30 \mathrm{~m} \text { af- } \\
\text { ter stent placement reduced } \\
\text { ischemic events through } \\
\text { reduction in MI and ST. With- } \\
\text { drawal of prasugrel was fol- } \\
\text { lowed by increase in MI after } \\
12 \text { and } 30 \mathrm{~m} \text { therapy }\end{array}$ \\
\hline \multirow[t]{5}{*}{$\begin{array}{l}\text { PEGASUS-TIMI } 54 \\
\text { NCT01225562 }\end{array}$} & $\begin{array}{c}\text { Bonaca et al. } \\
\text { NEJM } 2015 \\
{[17]}\end{array}$ & $\begin{array}{c}21,162 \text { pts } \\
1 \text { to } 3 \text { years after MI }\end{array}$ & \multirow{5}{*}{$\begin{array}{l}\text { tic } 2 \times 90 \mathrm{mg} \\
\text { and ASA vs. } \\
\text { tic } 2 \times 60 \mathrm{mg} \\
\text { and ASA vs. placebo } \\
\text { and ASA up to } 36 \mathrm{~m}\end{array}$} & $\begin{array}{c}\text { DAPT reduced risk of CV } \\
\text { death, MI, or stroke and in- } \\
\text { creased risk of major bleeding }\end{array}$ \\
\hline & $\begin{array}{l}\text { Bhatt et al. } \\
\text { JACC } 2016 \\
\text { [18] }\end{array}$ & $\begin{array}{c}21,162 \text { pts } \\
\text { DM }(n=6806) \\
\text { No-DM }(n=14,355) \\
1 \text { to } 3 \text { years after MI }\end{array}$ & & $\begin{array}{l}\text { In pts with DM DAPT reduced } \\
\text { risk of recurrent ischemic } \\
\text { events including CV death } \\
\text { and CHD death }\end{array}$ \\
\hline & $\begin{array}{l}\text { Bonaca et al. } \\
\text { JACC } 2016 \\
{[19]}\end{array}$ & $\begin{array}{c}21,162 \text { pts } \\
\text { PAD ( } \mathrm{n}=1143) \\
\text { No-PAD ( } \mathrm{n}=20,017) \\
1 \text { to } 3 \text { years after } \mathrm{Ml}\end{array}$ & & $\begin{array}{l}\text { DAPT reduced MACE and } \\
\text { MALE in PAD patients }\end{array}$ \\
\hline & $\begin{array}{l}\text { Bonaca et al. } \\
\text { EHJ } 2016 \\
{[20]}\end{array}$ & $\begin{array}{c}18,761 \text { pts } \\
1 \text { to } 3 \text { years after MI } \\
\text { DAPT cessation prior } \\
\text { to randomization: } \\
\leq 30 \text { days }(n=7181) \\
>30 \text { days to } 1 \text { year } \\
(n=6501) \\
>1 \text { year }(n=5079)\end{array}$ & & $\begin{array}{l}\text { The benefit of DAPT was } \\
\text { higher in pts continuing on or } \\
\text { re-starting early after interrup- } \\
\text { tion of P2Y12 inhibition when } \\
\text { compared with pts stable } \\
>2 \text { years from MI and off } \\
\text { P2Y12 inhibitor }>1 \text { year. The } \\
\text { increase in bleeding events } \\
\text { with ticagrelor was similar re- } \\
\text { gardless of this time interval }\end{array}$ \\
\hline & $\begin{array}{l}\text { Bansilal et al. } \\
\text { JACC } 2018 \text { [21] }\end{array}$ & $\begin{array}{c}21,162 \mathrm{pts} \\
\text { MVD } \\
\text { ( } \mathrm{n}=12,558 \mathrm{pts}) \\
\text { No-MVD } \\
\text { ( } \mathrm{n}=8600 \mathrm{pts}) \\
1 \text { to } 3 \text { years after } \mathrm{Ml}\end{array}$ & & $\begin{array}{l}\text { In pts with MVD DAPT } \\
\text { reduced risk of MACE } \\
\text { and CE, and increased } \\
\text { the risk of major bleeding, } \\
\text { but not } \mathrm{ICH} \text { or fatal bleeding }\end{array}$ \\
\hline
\end{tabular}

ASA - acetylsalicylic acid; BMS — bare-metal stent; CE — coronary events (coronary death, MI, or stent thrombosis); CHD — coronary heart disease; clo - clopidogrel; CV - cardiovascular; DAPT — dual antiplatelet therapy; DES — drug-eluting stent; DM - diabetes mellitus; $\mathrm{ICH}$ - intracranial hemorrhage; MACCE - major adverse CV and cerebrovascular events (death, MI, or stroke); MACE — major adverse CV events (CV death, MI, or stroke); MALE - major adverse limb events (acute limb ischemia or peripheral revascularization for ischemia); MI myocardial infarction; MVD - multivessel disease; PAD - peripheral artery disease; pra - prasugrel; pts - patients; riv — rivaroxaban; ST — stent thrombosis; TAXUS — paclitaxel-eluting stent; tic — ticagrelor

ducted in various populations (Table 5) [14-22]. Inclusion and exclusion criteria as well as the profile of patients enrolled in these trials should be used to determine indications for particular agents. 
Table 5 (cont.). Clinical trials supporting the 2019 European Society of Cardiology (ESC) guidelines for the diagnosis and management of chronic coronary syndromes (according to citations) [14-22].

\begin{tabular}{lcccc}
\hline $\begin{array}{l}\text { Study } \\
\text { ClinicalTrials.gov }\end{array}$ & Publication & Patients & Study treatment & Outcome \\
\hline $\begin{array}{l}\text { COMPASS } \\
\text { NCT01776424 }\end{array}$ & $\begin{array}{c}\text { Eikelboom et al. } \\
\text { NEJM 2017 } \\
{[22]}\end{array}$ & $\begin{array}{c}27,395 \text { pts } \\
\text { with stable } \\
\text { atherosclerotic } \\
\text { vascular disease }\end{array}$ & $\begin{array}{c}\text { riv } 2 \times 2.5 \text { mg and } \\
\text { ASA vs. riv } 2 \times 5 \text { mg } \\
\text { and placebo vs. } \\
\text { placebo and ASA }\end{array}$ & $\begin{array}{c}\text { Pts assigned to riv plus ASA } \\
\text { had better CV outcomes and } \\
\text { more major bleeding events } \\
\text { than those assigned to ASA } \\
\text { alone. Riv alone did not result } \\
\text { in better CV outcomes than } \\
\text { ASA alone and resulted in } \\
\text { more major bleeding events }\end{array}$ \\
\hline
\end{tabular}

ASA - acetylsalicylic acid; BMS — bare-metal stent; CE — coronary events (coronary death, MI, or stent thrombosis); CHD — coronary heart disease; clo - clopidogrel; CV - cardiovascular; DAPT — dual antiplatelet therapy; DES — drug-eluting stent; DM - diabetes mellitus; $\mathrm{ICH}$ - intracranial hemorrhage; MACCE - major adverse CV and cerebrovascular events (death, MI, or stroke); MACE - major adverse CV events (CV death, MI, or stroke); MALE - major adverse limb events (acute limb ischemia or peripheral revascularization for ischemia); MI myocardial infarction; MVD - multivessel disease; PAD - peripheral artery disease; pra — prasugrel; pts — patients; riv — rivaroxaban;

ST — stent thrombosis; TAXUS — paclitaxel-eluting stent; tic — ticagrelor

\section{Dual antiplatelet therapy with ASA and a P2Y12 receptor inhibitor}

Tolerability of DAPT during the recommended 12-month therapy period and reduction of the risk of ischemic events outweighing the elevated bleeding risk is a premise for prolonged therapy with a P2Y12 receptor inhibitor and ASA [23-25]. According to the citations in the ESC guidelines $[10,11]$, indications to use clopidogrel, prasugrel, or ticagrelor in combination with ASA in patients with CCS after ACS are based on the data coming from the DAPT [14, 15, 26], TL-PAS [16], and PEGASUS-TIMI 54 trials [17-21].

The Dual Antiplatelet Therapy (DAPT) trial assessed the benefits and risks of 30 vs. 12 months of DAPT with a thienopyridine derivate (clopidogrel or prasugrel) and ASA in patients with ischemic heart disease due to stenotic or occlusive lesions in either native coronary arteries or coronary artery bypass grafting treated with stent implantation $[14,15,26]$. The choice of thienopyridine and its dose followed the local standard of practice in the study sites. Out of the 11,648 randomized patients (9961 treated with drug-eluting stents [DES], 1687 with bare-metal stents [BMS]), 30.7\% presented with MI. After 12 months of DAPT, patients were randomly assigned to continue treatment with thienopyridine or placebo for another 18 months; all patients continued receiving ASA. Continuation of DAPT beyond 1 year after DES implantation, as compared with ASA therapy alone, significantly reduced the risk of stent thrombosis ( $0.4 \%$ vs. $1.4 \%$; hazard ratio [HR] $0.29 ; \mathrm{p}<0.001$ ), MI (2.1\% vs. $4.1 \%$; HR $0.47 ; \mathrm{p}<0.001)$, MI not related to stent thrombosis ( $1.8 \%$ vs. $2.9 \%$; HR
$0.59 ; \mathrm{p}<0.001$ ), and major adverse cardiovascular and cerebrovascular events $(4.3 \%$ vs. $5.9 \%$; HR 0.71 (95\% confidence interval [CI] 0.59-0.85; $\mathrm{p}<0.001$ ), but was associated with an increased risk of moderate or severe bleeding (2.5\% vs. $1.6 \%$, $\mathrm{p}=0.001)$. An elevated risk of stent thrombosis and MI was observed in both groups during the first 3 months after discontinuation of thienopyridine treatment [14]. The risk of death from any cause was higher in the group that continued to receive thienopyridine as compared with the placebo group (2.0\% vs. $1.5 \%$; HR 1.36 ; $p=0.05)$. During the secondary-analysis period (month 12 to month 33) the rate of all-cause mortality was higher in the thienopyridine group: $2.3 \%$ vs. $1.8 \%$, respectively (HR 1.36; $\mathrm{p}=0.04$ ). The difference was driven by an increase in the number of non-cardiovascular deaths (mainly related to bleeding, fatal trauma, and cancer) in the thienopyridine group. It is not clear what proportion of these deaths was related to evaluated treatment, as some of the deaths not defined as bleeding-related were mediated by bleeding [14].

The TAXUS Liberté Post Approval Study (TL-PAS) - a subpopulation of DAPT — included patients who were treated with a TAXUS Liberté paclitaxel-eluting stent and prasugrel [16]. The TL-PAS patients represented the largest group of patients implanted with a paclitaxel-eluting coronary stent, and the largest cohort receiving prasugrel, enrolled into the DAPT study. The occurrence of the DAPT study co-primary composite end point (death, MI, or stroke) was lower in patients receiving the combination of prasugrel and ASA for 30 months compared with 12 months (3.7\% vs. $8.8 \%$; HR 0.407 ; $p<0.001$ ) solely through the 
reduction in MI rate $(1.9 \%$ vs. $7.1 \%$; HR 0.255 ; $\mathrm{p}<0.001)$. The incidence of stent thrombosis was also lower with longer dual antiplatelet therapy $(0.2 \%$ vs. $2.9 \%$; HR $0.063 ; p<0.001)$. Rates of death and stroke were similar in both groups. Withdrawal of prasugrel was followed by an increase in the rate of MI after both 12 and 30 months of therapy. The optimal duration of DAPT with prasugrel after implantation of a TAXUS Liberté paclitaxel-eluting stent remains unknown, but it appears to be longer than 30 months [16].

The results of this study are of limited relevance because paclitaxel-eluting stents are no longer used due to the increased risk of major adverse cardiac events mainly driven by a higher rate of MI, target-vessel revascularization, and stent thrombosis, especially a very late one [27, 28].

The PEGASUS-TIMI 54 (Prevention of Cardiovascular Events in Patients with Prior Heart Attack Using Ticagrelor Compared to Placebo on a Background of Aspirin-Thrombolysis In Myocardial Infarction 54) trial was designed to test the hypothesis that long-term therapy with ticagrelor added to low-dose ASA reduces the risk of major adverse cardiovascular events (MACE) in stable patients with a history of MI [17]. Patients were randomized in a 1:1:1 ratio to receive ticagrelor $90 \mathrm{mg}$ b.i.d., $60 \mathrm{mg}$ b.i.d., or placebo. Reduction in the primary end point (MACE: composite of cardiovascular death, MI, or stroke) in both ticagrelor-treated study arms $(7.85 \%$ and $7.77 \%$, respectively) vs. placebo $(9.04 \%)$ at 3 years of follow-up was observed (HR for ticagrelor $90 \mathrm{mg}$ b.i.d. vs. placebo, 0.85; $\mathrm{p}=0.008$; HR for ticagrelor $60 \mathrm{mg}$ b.i.d. vs. placebo, 0.84; $\mathrm{p}=0.004)$. Differences promoting therapy with a combination of ticagrelor and ASA over ASA alone were shown in the rate of MI (HR for ticagrelor $90 \mathrm{mg}$ b.i.d. vs. placebo, $0.81 ; \mathrm{p}=0.01$; HR for ticagrelor $60 \mathrm{mg}$ b.i.d. vs. placebo, $0.84 ; \mathrm{p}=0.03$ ) and in the rate of stroke; however, in the latter case, only for ticagrelor $60 \mathrm{mg}$ b.i.d. vs. placebo ( $1.47 \%$ vs. $1.94 \%$; HR $0.75 ; \mathrm{p}=0.03)$. As far as safety of the treatment is concerned, major bleedings were more frequent in individuals receiving ticagrelor, either $90 \mathrm{mg}$ b.i.d. or $60 \mathrm{mg}$ b.i.d., compared with those in whom placebo was administered, $2.6 \%$ and $2.3 \%$ vs. $1.06 \%$, respectively (HR for ticagrelor $90 \mathrm{mg}$ b.i.d., 2.69; p < 0.001; HR for ticagrelor $60 \mathrm{mg}$, 2.32; $\mathrm{p}<0.001$ ); however, no differences were found in the rates of fatal or non-fatal intracranial bleeding episodes in the ticagrelor-treated arms as compared with placebo $(0.63 \%$ and $0.71 \%$, vs. $0.60 \%$, respectively) [17].
Out of the 21,162 patients enrolled in the PEGASUS-TIMI 54 trial, 6806 had diabetes [18]. Because patients with diabetes have a higher risk of MACE, the absolute risk reduction tended to be greater in patients with vs. without diabetes $(1.5 \%$ vs. $1.1 \%$, respectively). Moreover, in patients with diabetes, ticagrelor reduced the rate of cardiovascular mortality by $22 \%(\mathrm{p}<0.05)$ and coronary heart disease deaths by $34 \%(\mathrm{p}=0.01)$ [18].

In a subset of patients with peripheral artery disease (PAD), the greater absolute risk reduction in MACE $(4.1 \%)$ was due to their higher absolute ischemic risk [19]. The $60 \mathrm{mg}$ b.i.d. dose of ticagrelor showed a particularly favorable impact on cardiovascular as well as all-cause mortality in comparison with placebo ( $4.2 \%$ vs. $9.6 \%$; HR $0.47 ; \mathrm{p}=0.014$ and $8.2 \%$ vs. $14.0 \%$; HR 0.52 ; $\mathrm{p}=0.0074)$ [19]. In patients with multi-vessel disease, ticagrelor reduced the risk of MACE $(7.94 \%$ vs. 9.37\%; HR 0.82; $\mathrm{p}=0.004)$, including reduction in coronary death (HR 0.64; $\mathrm{p}=0.002$ ) [21].

The analysis of results according to the time between randomization to the PEGASUS-TIMI 54 trial and previous cessation of DAPT with P2Y12 inhibitor and ASA after MI revealed better outcomes in patients who had stopped DAPT more recently [20]. Patients were categorized by time from the last P2Y12 receptor inhibitor dose (days: $\leq 30,30-360,>360$ ). The benefit of ticagrelor (reduction in MACE rate) depended on the time from the last dose, and was more pronounced in patients continuing on or re-starting after only a brief interruption of P2Y12 inhibition than in patients who had proven themselves stable more than 2 years from MI and off P2Y12 inhibitor therapy for more than a year with hazard ratios for ticagrelor (pooled doses) vs. placebo of 0.73 ; $p<0.001,0.86 ; p=0.11$, and $1.01 ; \mathrm{p}=0.96$, respectively, by category (P-trend for interaction $<0.001$ ). The benefit within 30 days of stopping DAPT was similar regardless of time from MI. On the other hand, the increase in bleeding events with ticagrelor was similar regardless of this time interval [20]. According to these results, the European Medicines Agency approved European (EU) label recommends that treatment with ticagrelor $60 \mathrm{mg}$ b.i.d. may be a continuation of the initial one-year treatment with ticagrelor $90 \mathrm{mg}$ b.i.d. (or other P2Y12 receptor inhibitor) in high-risk patients with MI [29]. Treatment with ticagrelor $60 \mathrm{mg}$ b.i.d. can also be initiated up to 2 years from the MI, or within 1 year after stopping previous P2Y12 receptor inhibitor treatment. Therefore, an analysis evaluating the efficacy and safety of treatment in a PEGASUS-TIMI 54 
subpopulation receiving low-dose ticagrelor recommended for treatment in the EU label $(n=10,779$ : 5388 in the ticagrelor $60 \mathrm{mg}$ b.i.d. and 5391 in the placebo group) was performed [30]. DATT with ticagrelor $60 \mathrm{mg}$ b.i.d. in the EU label population reduced the composite of cardiovascular death, MI, or stroke (7.9\% vs. $9.6 \%$; HR $0.80 ; p=0.001)$. Moreover, in the EU label population this DATT strategy was associated with lower hazard ratios for cardiovascular death $(0.71 ; \mathrm{p}=0.0041)$, MI $(0.83$; $\mathrm{p}=0.041)$, and all-cause death $(0.80 ; \mathrm{p}=0.018)$. Better efficacy was associated with a higher risk of Thrombolysis in Myocardial Infarction (TIMI) major bleeding occurrence (2.5\% vs. $1.1 \%$; HR 2.36; $\mathrm{p}<0.001$ ), without an increase in fatal or intracranial bleedings, confirming a favorable benefit-risk balance for long-term ticagrelor $60 \mathrm{mg}$ b.i.d. in this population [30, 31].

Ticagrelor proved to be similarly effective in patients with and without a history of coronary stenting, suggesting also a benefit in the prevention of spontaneous atherothrombotic events not related to stent thrombosis [32].

The increased risk of non-cardiovascular death in patients receiving clopidogrel or prasugrel in comparison with the placebo group in the DAPT trial [14], in contrast to the decreased risk of cardiovascular death and all-cause death seen in patients treated with low-dose ticagrelor in the EU label population of the PEGASUS-TIMI 54 trial [30], resulted in inclusion in the 2020 ESC NSTE-ACS guidelines the recommendation for use of clopidogrel or prasugrel only if the patient is not eligible for treatment with ticagrelor [11].

\section{Dual antithrombotic therapy with ASA and rivaroxaban}

Continued occurrence of recurrent ischemic events despite treatment with potent P2Y12 receptor inhibitors (prasugrel and ticagrelor) and ASA stimulated interest in exploring the efficacy and safety of direct oral anticoagulants in patients with ACS [33].

Reduction in ischemic event risk with rivaroxaban ( $2.5 \mathrm{mg}$ or $5 \mathrm{mg}$ b.i.d.) added to standard DAPT with ASA and a P2Y12 inhibitor has been shown to be superior to placebo in patients with ACS in the ATLAS ACS 2-TIMI 51 trial. However, only the $2.5 \mathrm{mg}$ b.i.d. dose of rivaroxaban was associated with a survival benefit. Moreover, the increase in risk of major bleeding was lower with the $2.5 \mathrm{mg}$ b.i.d. rivaroxaban dose [34]. These results provided a promising basis for low-dose rivaroxaban in addition to ASA in patients with CCS.

According to the citations in the ESC guidelines $[10,11]$, the indications for use of rivaroxaban in combination with ASA in patients with CCS after ACS are based on the results of the Cardiovascular Outcomes for People Using Anticoagulation Strategies (COMPASS) trial [22, 35-37].

The COMPASS trial was aimed to test the hypothesis that rivaroxaban in combination with ASA or given alone is more effective than ASA alone in preventing recurrent cardiovascular events, with acceptable safety, in patients with stable atherosclerotic vascular disease [22]. Patients with stable atherosclerotic vascular disease were randomly assigned to receive rivaroxaban $(2.5 \mathrm{mg}$ b.i.d.) plus ASA (100 mg q.d.), rivaroxaban (5 mg b.i.d.), or ASA (100 mg q.d.) in a 1:1:1 ratio. The prevalence of the primary outcome composed of cardiovascular death, stroke, or MI was lower in the rivaroxaban-plus-ASA group than in the ASA-alone group (4.1\% vs. $5.4 \%$; HR 0.76; $\mathrm{p}<0.001$ ). Moreover, all-cause mortality and cardiovascular mortality rates were lower in the rivaroxaban-plus-ASA group as compared with the ASA-alone group (for all-cause mortality: $3.4 \%$ vs. $4.1 \%$; HR 0.82 ; $\mathrm{p}=0.01$; for cardiovascular mortality: $1.7 \%$ vs. $2.2 \%$; HR $0.78 ; \mathrm{p}=0.02$ ). Superiority of DATT with low rivaroxaban dose and ASA over ASA alone was observed also for the risk of stroke $(0.9 \%$ vs. $1.6 \%$; HR 0.58; $\mathrm{p}<0.001)$. This benefit was achieved at the cost of a higher major bleeding rate in the rivaroxaban-plus-ASA group (3.1\% vs. $1.9 \%$; HR $1.70 ; \mathrm{p}<0.001)$, but with no significant difference in fatal bleeding ( $0.2 \%$ vs. $0.1 \%$; HR $1.49 ; \mathrm{p}=0.32)$. A substantial reduction in ischemic strokes and embolic/uncertain strokes with low-dose rivaroxaban and ASA was also confirmed in an additional analysis of this trial [38], suggesting a potential for this new antithrombotic option in primary and secondary stroke prevention. Favorable clinical outcome with DATT was also confirmed by an analysis of net clinical benefit [37].

No clinical benefit with regard to the primary outcome was observed in the $5 \mathrm{mg}$ b.i.d. rivaroxaban-alone group as compared with the ASA-alone group, but major bleeding events occurred more frequently in the rivaroxaban-alone group. The study was prematurely terminated due to the superiority of the rivaroxaban-plus-ASA therapy after a mean follow-up of 23 months [22]. In patients with stable coronary artery disease (CAD) $(n=24,824)$, addition of rivaroxaban to ASA resulted in a similar 
impact on the efficacy and safety of the treatment. DATT with rivaroxaban and ASA compared with ASA alone reduced the primary outcome $(4 \%$ vs. $6 \%$; HR $0.74 ; \mathrm{p}<0.0001$ ) and mortality (3\% vs. $4 \%$; HR 0.77; $\mathrm{p}=0.0012)$, but increased the rate of major bleeding ( $3 \%$ vs. $2 \%$; HR 1.66 ; $<<0.0001)$ [35]. There were 17,028 patients $(69 \%)$ with a history of previous MI; however, patients who gained the most in the PEGASUS-TIMI 54 trial (EU label population), i.e. those between the first and second year after MI (72.9\% of the total population), in the COMPASS trial accounted for only $9.3 \%$ of all patients with CAD. Together with patients within the first year after MI, this subpopulation of CAD patients in the COMPASS trial accounted for $14.3 \%$, and according to a subgroup analysis the clinical benefit in terms of the primary outcome was not significant, in contrast to patients over 5 years after MI [35].

Of the 16,560 patients with CCS in the COMPASS trial, $9862(59.6 \%)$ patients had a history of previous percutaneous coronary intervention (PCI). The average time from PCI to randomization was 5.4 years. DATT with rivaroxaban compared with ASA alone in patients with or without previous $\mathrm{PCI}$ resulted in consistent MACE reduction (PCI: $4.0 \%$ vs. $5.5 \%$; HR 0.74 ; no PCI: $4.4 \%$ vs. $5.7 \%$; HR 0.76; P-interaction $=0.85$ ) and mortality reduction (PCI: $2.5 \%$ vs. $3.5 \%$; HR 0.73; no PCI: $4.1 \%$ vs. $5.0 \%$; HR 0.80; P-interaction $=0.59$ ), but was associated with an increased rate of major bleeding (PCI: $3.3 \%$ vs. $2.0 \%$; HR 1.72; no PCI: $2.9 \%$ vs. 1.8\%; HR 1.58, P-interaction $=0.68$ ) [38]. Among those with previous PCI 1 year and beyond, the effects on MACE and mortality were consistent irrespective of time since last $\mathrm{PCI}$ and irrespective of a history of previous MI (P-interaction $=0.64)$ [39].

The combination of ASA plus rivaroxaban provided a similar relative degree of clinical benefit in patients with and without diabetes mellitus. However, due to a higher baseline risk, the absolute benefits appeared larger in patients with diabetes mellitus, including a 3 -fold greater reduction in all-cause mortality [36].

\section{Patient characteristics in trials supporting recommendation for DATT in CCS patients after MI}

Different inclusion and exclusion criteria in trials supporting the ESC guidelines [10] displayed in Table 6 lead to several pivotal differences in the characteristics of patients enrolled to these trials (Table 7). Patients after ischemic stroke were included into the DAPT, TL-PAS, and COMPASS trials, but not into the PEGASUS-TIMI 54 trial. Only $36 \%$ of subjects in the COMPASS trial had a history of previous PCI, while in the PEGASUS-TIMI 54, DAPT, and TL-PAS trials this percentage was $83 \%$, $100 \%$, and $100 \%$, respectively. All patients in the PEGASUS-TIMI 54, 62.6\% in COMPASS, and only $21.6 \%$ in the DAPT trial had a history of MI before enrolment into the trial. Finally, a huge difference regarding the interval between $\mathrm{MI}$ and randomization in the PEGASUS-TIMI 54 (1.7 year) and COMPASS trial (7.1 years) should be highlighted. Several minor differences between the investigated populations should also be noted [17-22, 34-36] (Table 7).

In the DAPT trial, an increased all-cause mortality risk was observed in patients on prolonged treatment with clopidogrel or prasugrel and ASA. Moreover, the reported clinical benefit of this therapeutic strategy (DAPT trial and TL-PAS) was mainly dependent on reduction of the risk of MI and stent thrombosis in patients in whom a paclitaxel-eluting coronary stent was implanted, while this type of stent is no longer in use due to increased risk of MI, target-vessel revascularization, and stent thrombosis, especially very late one. Furthermore, the results of separate analyses for clopidogrel and prasugrel failed to demonstrate any significant impact on the clinical outcome [14-16, 26-28]. When considering treatment with clopidogrel, its volatile pharmacodynamic effects related to variable efficiency of conversion to its active metabolite, partly associated with loss-of-function variants in the CYP2C19 gene, leading to a lack of efficacy in some patients, should be taken into account [40-43].

Thus, the rationale to recommend prolonged DAPT with any of these drugs, in our opinion, is limited.

In contrast to the DAPT trial and TL-PAS, the messages provided by the PEGASUS-TIMI 54 and COMPASS trials seem to be clear and unambiguously positive for DATT with ticagrelor $60 \mathrm{mg} \mathrm{mg}$ b.i.d. and rivaroxaban $2.5 \mathrm{mg}$ b.i.d., respectively. However, the indications for DATT including ticagrelor or rivaroxaban need to be clarified because the overlapping of eligibility between PEGASUS-TIMI 54 and COMPASS criteria (Fig. 1) is not reflected by overlapping of evaluated populations according to patient characteristics of both trials (Table 6,7 ).

\section{PEGASUS-TIMI 54 versus COMPASS approach}

In an attempt to answer the question: "Who could benefit most from the PEGASUS-TIMI 54 
Table 6. Inclusion and exclusion criteria of clinical trials supporting the 2019 European Society of Cardiology (ESC) guidelines.

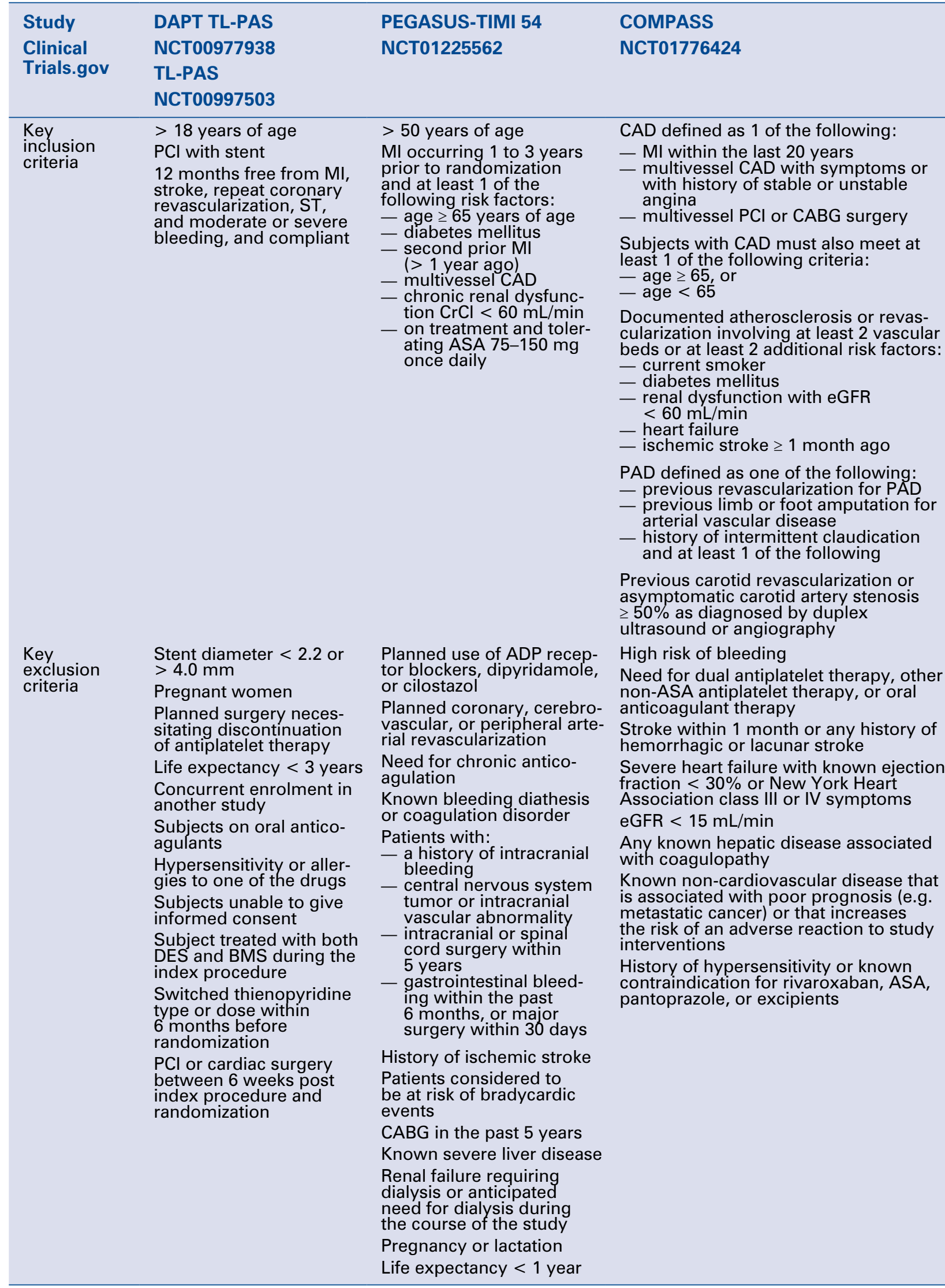

ASA - acetylsalicylic acid; BMS — bare-metal stent; CABG — coronary artery bypass grafting; CAD — coronary artery disease; CrCl creatinine clearance; DES - drug-eluting stent; eGFR - estimated glomerular filtration rate; MI — myocardial infarction; PAD - peripheral artery disease; $\mathrm{PCl}$ - percutaneous coronary intervention; ST — stent thrombosis 
Table 7. Study population characteristics of trials supporting the 2019 European Society of Cardiology (ESC) guidelines.

\begin{tabular}{|c|c|c|c|}
\hline $\begin{array}{l}\text { Study } \\
\text { ClinicalTrials.gov }\end{array}$ & $\begin{array}{c}\text { DAPT } \\
\text { NCT00977938 } \\
\text { TL-PAS } \\
\text { NCT00997503 }\end{array}$ & $\begin{array}{l}\text { PEGASUS-TIMI } 54 \\
\text { NCT01225562 }\end{array}$ & $\begin{array}{c}\text { COMPASS } \\
\text { NCT01776424 }\end{array}$ \\
\hline Number of patients & 11,648 & 21,162 & 27,395 \\
\hline Number of CAD patients & 11,648 & 21,162 & 24,824 \\
\hline CAD patients [\%] & 100 & 100 & 90.6 \\
\hline Age [years] & $61.7 \pm 10.2$ & $65.3 \pm 8.4$ & $68.2 \pm 7.9$ \\
\hline Female sex [\%] & 25.4 & 23.9 & 22.0 \\
\hline Diabetes mellitus [\%] & 30.6 & 32.2 & 37.8 \\
\hline Hypertension [\%] & 74.9 & 77.5 & 75.3 \\
\hline Tobacco use [\%] & 24.6 & 16.7 & 21.4 \\
\hline Previous stroke [\%] & 3.3 & 0 & 3.8 \\
\hline Heart failure [\%] & 4.7 & 20.0 & 21.5 \\
\hline Peripheral arterial disease [\%] & 5.8 & 5.4 & 27.3 \\
\hline Chronic kidney disease (GFR $<60 \mathrm{~mL} / \mathrm{min}$ ) [\%] & 4.23 & 23,2 & 23.1 \\
\hline Previous $\mathrm{PCl}[\%]$ & 100 & 83.0 & 36 \\
\hline Previous MI [\%] & 21.6 & 100 & 62.2 \\
\hline Previous STEMI [\%] & 10.5 & 53.6 & NA \\
\hline Years since MI [median] & 1 & 1.7 & 7.1 \\
\hline $\begin{array}{l}\text { Patients with previous MI within 1-2 years [\%] } \\
\text { *based on DAPT cessation } \\
{ }^{* *} \text { out of CAD subpopulation }\end{array}$ & NA & $72.9 *$ & $9.3^{* *}$ \\
\hline Duration of study treatment [months] & 30 & 33 & 23 \\
\hline $\begin{array}{l}\text { Discontinuation rate in the study arm [\%] } \\
{ }^{*} \text { ticagrelor } 60 \mathrm{mg} \text { b.i.d. } \\
{ }^{* *} \text { rivaroxaban } 2.5 \mathrm{mg} \text { b.i.d. + ASA }\end{array}$ & 21.4 & $28.7^{*}$ & $16.5^{* *}$ \\
\hline
\end{tabular}

ASA - acetylsalicylic acid; CAD — coronary artery disease; DAPT — dual antiplatelet therapy; GFR — glomerular filtration rate; MI — myocardial infarction; $\mathrm{NA}$ - non available; $\mathrm{PCl}$ - percutaneous coronary intervention; STEMI — ST-segment elevation myocardial infarction

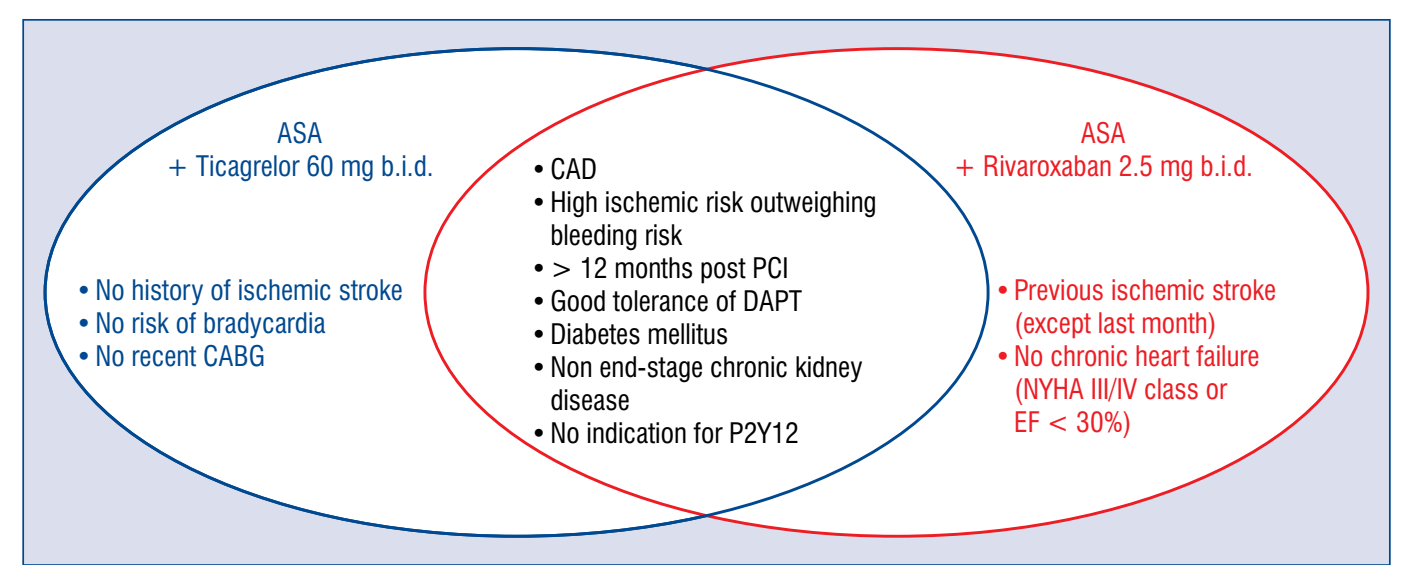

Figure 1. Overlapping of PEGASUS-TIMI 54 and COMPASS trials inclusion criteria; DAPT — dual antiplatelet therapy; CAD - coronary artery disease; CABG — coronary artery bypass grafting; EF — ejection fraction; NYHA — New York Heart Association; $\mathrm{PCl}$ - percutaneous coronary intervention. 
rather than from the COMPASS approach among CAD patients?", Brunetti et al. [44] proposed a flow-chart for identification of the optimal treatment, based solely on the PEGASUS-TIMI 54 and COMPASS trial inclusion and exclusion criteria. According to the authors, the choice between rivaroxaban and ticagrelor should be based on the presence of severe renal failure (defined as estimated glomerular filtration rate $<15 \mathrm{~mL} / \mathrm{min}$ ), severe heart failure (ejection fraction $<30 \%$ or New York Heart Association [NYHA] class III or IV symptoms), or strong interaction with CYP3A4 or P-glycoprotein, the presence of which indicates the PEGASUS-TIMI 54 approach [44]. The proposed strategy may be helpful in some, but probably few subjects, leaving the dilemma of choosing between ticagrelor and rivaroxaban unresolved in a majority of post-MI patients with a high risk of ischemic events and without high bleeding risk.

A similar algorithm was developed by Capodanno et al. [45]; however, in this case previous ischemic stroke was the only differentiating factor between the recommended DATT strategies. There is no doubt that this factor should be taken into account due to the differences in the PEGASUS-TIMI 54 and COMPASS inclusion and exclusion criteria. Nevertheless, considering that none of the patients included in the PEGASUS-TIMI 54 trial and only $3.8 \%$ of patients in the COMPASS trial experienced ischemic stroke previously (Table 7), the evidence to support this recommendation is weak, and the vast majority of post-MI subjects requiring DATT will remain without clear indications, with both strategies deemed by the authors equally acceptable in patients without a prior stroke [45]. The statement that candidates for the PEGASUS-TIMI 54 trial strategy might mostly benefit from uninterrupted DAPT after the recommended 12-month course of DAPT after MI [45] is indeed supported by the analysis of the trial results [21], showing the highest benefit of DATT with ticagrelor in patients continuing on or re-starting after only a brief interruption of P2Y12 inhibition. On the other hand, according to the subgroup analysis of the COMPASS trial, the clinical benefit in terms of primary outcome, despite a clear trend, was not significant in patients enrolled within 2 years of MI. Unquestionable superiority of treatment with low rivaroxaban dose in combination with ASA over ASA alone was seen in subjects over 5 years after MI [35].

The superiority of DATT with low-dose rivaroxaban over ASA alone in patients with CAD and PAD was pointed out by Ramacciotti et al. [46]. The
$18 \%$ mortality reduction with rivaroxaban added to ASA is a unique finding; however, it is difficult to accept the statement that this strategy simply represents a paradigm shift for all patients requiring secondary prevention, because the COMPASS trial population is very different from the PEGASUS-TIMI 54 trial population (Table 7).

According to González-Juanatey et al. [47], during the first year after ACS, DAPT should be recommended, but after 12 months the ischemic and bleeding risk should be re-evaluated and among patients with high-risk features, and switching from DAPT to the COMPASS regimen should be strongly considered. This interesting concept, however, before being taken under consideration, should first be assessed in a clinical trial, because cessation of DAPT is associated with an increased risk of thrombotic events [14, 20], and evidence regarding the efficacy and safety of switching from a P2Y12 receptor inhibitor to rivaroxaban is lacking.

Besides antithrombotic therapy in a setting of low bleeding risk, multifactorial interventions including lipid-lowering treatment in high-risk CAD patients might be a promising option to significantly improve the prognosis [48].

In order to apply a proper strategy of treatment to a post-ACS patient remaining in sinus rhythm, several factors need to be considered (Fig. 2):

- risk of cardiovascular ischemic events;

- risk of bleeding events;

- current antiplatelet treatment;

- time since last ACS;

- time since DAPT termination;

- type of implanted stent;

- known hypersensitivity to treatment with rivaroxaban and ticagrelor, prasugrel, or clopidogrel;

- comorbidities: history of ischemic stroke, recent coronary artery bypass grafting, risk of bradycardia, renal insufficiency with estimated glomerular filtration rate $<15 \mathrm{~mL} /$ min, heart failure with ejection fraction $<30 \%$ or NYHA class III or IV, PAD or other atherothrombotic multiple vascular bed involvement (AMVBI). For patients who discontinued their DAPT before 12 months after ACS due to intolerance of P2Y12 receptor inhibitor or ASA, treatment with one antiplatelet agent or a switch to another antithrombotic agent should be considered.

Regardless of the treatment strategy chosen, the basis of effectiveness is patient adherence to medication. Therefore, health education aimed at explaining the purpose of therapy should be applied [49-54]. 


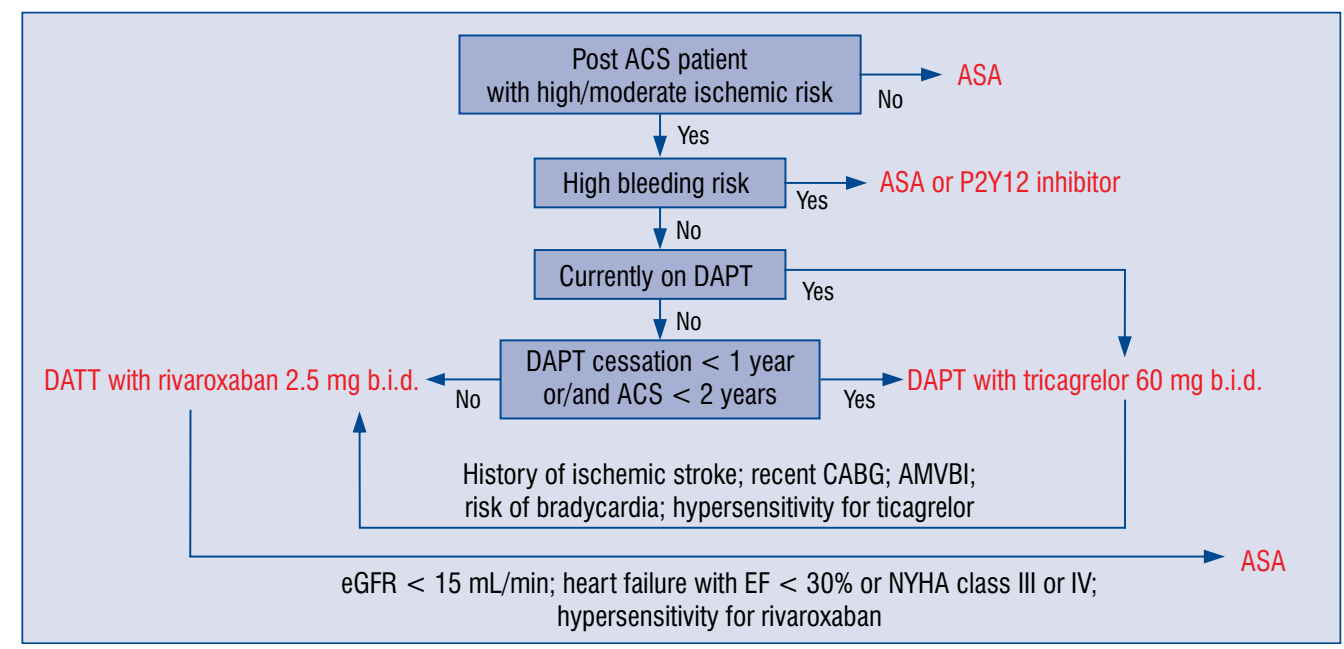

Figure 2. A schematic algorithm for drug assignment for prolonged antithrombotic treatment in patients $>12$ months after acute coronary syndrome (ACS) in sinus rhythm; ASA — acetylsalicylic acid; AMVBI — atherothrombotic multiple vascular bed involvement; CABG — coronary artery bypass grafting; DAPT — dual antiplatelet therapy; eGFR — estimated glomerular filtration rate; EF — ejection fraction; NYHA — New York Heart Association.

Thus, implementation of a multidisciplinary approach involving a proper selection of patients with high risk for thrombosis and low risk for bleeding may help to achieve long-term anti-ischemic benefits with low bleeding risk. The latter approach should be based on the assessment of individual patient's propensity for thrombosis and bleeding in conjunction with demographic and clinical variables. Finally, stratification of patients for continued DAPT with ASA and low dose of ticagrelor vs. switching to combination therapy with ASA plus very low dose of rivaroxaban and finding the correct timing for this transition still poses a challenge. There is urgent need for a study investigating this issue. Potential utility of biomarkers or assays for platelet function and thrombin pathway function assessment remains an unexplored area in the stratification of patients for long-term therapy [55].

\section{Summary}

The comparison of the PEGASUS-TIMI 54 and COMPASS trial patient characteristics clearly shows that each of these treatment strategies should be addressed at different groups of patients. A greater benefit in post-ACS patients with a high risk of ischemic events and without high bleeding risk may be expected with ASA and ticagrelor $60 \mathrm{mg}$ b.i.d. when the therapy is continued without interruption or with short interruption only after ACS. On the other hand, ASA and rivaroxaban $2.5 \mathrm{mg}$ b.i.d. seems to be a better option when indications for DATT appear after a longer time from ACS (more than 2 years) and/or from cessation of DAPT (more than 1 year) and in patients with multiple vascular bed atherosclerosis. Thus, both options of DATTs complement each other rather than compete, as can be presumed from the recommendations. However, a direct comparison between these strategies should be probably tested in future clinical trials.

Conflict of interest: Jacek Kubica - speaker and consultancy honoraria from: AstraZeneca, Bayer, Boehringer Ingelheim, Orion Pharma; Piotr Adamski - speaker honoraria from: AstraZeneca; Piotr Niezgoda - none; Dimitrios Alexopoulos speaker and consultancy honoraria from: AstraZeneca, Bayer, Pfizer, Boehringer Ingelheim, Medtronic, Biotronik; Jolita Badarienè — speaker honoraria from: Boehringer Ingelheim, Servier, Bayer; grants from: Amgen, AstraZeneca; Andrzej Budaj - grants and personal fees from AstraZeneca; grants from Sanofi; grants and personal fees from Bristol-Myers Squibb/Pfizer; grants from Boehringer-Ingelheim and Novartis; grants and personal fees from GlaxoSmithKline; and grants from Eisai outside the submitted work; Katarzyna Buszko - none; Dariusz Dudek — none; Tomasz Fabiszak — none; Mariusz Gąsior - speaker honoraria from: AstraZeneca; Robert Gil - speaker honoraria from: AstraZeneca; Diana A. Gorog - speaker honoraria from: AstraZeneca, Bayer, Boehringer Ingelheim; Institutional grant from Bayer; Stefan Grajek — speaker 
honoraria from: AstraZeneca, Bayer, Servier; Paul A. Gurbel - grants and personal fees from: Bayer HealthCare LLC, Otitopic Inc., Amgen, Janssen, and US WorldMeds LLC; grants from: Instrumentation Laboratory, Haemonetics, Medicure Inc., Idorsia Pharmaceuticals, and Hikari Dx; personal fees from: UpToDate; relator and expert witness in litigation involving clopidogrel; two patents: Detection of restenosis risk in patients issued and Assessment of cardiac health and thrombotic risk in a patient; Marcin Gruchała — none; Miłosz J. Jaguszewski - speaking fees and travel grants from: Boheringer Ingelheim, Bayer, AstraZeneca, and Pfizer outside the submitted work; Stefan James - institutional research grants from: AstraZeneca, Bayer, Jansen, The Medicines Company, Abbot Vascular and Boston Scientific; honoraria from: AstraZeneca, Bayer, and Medtronic; Young-Hoon Jeong — speaker honoraria from: AstraZeneca, Daiichi Sankyo, Sanofi-Aventis, Han-mi Pharmaceuticals and Yuhan Pharmaceuticals; and research grants or support from: Yuhan Pharmaceuticals and U\&I Corporation; Bernd Jilma — none; Jarosław D. Kasprzak speaker honoraria from: AstraZeneca, Bayer; Andrzej Kleinrok - none; Aldona Kubica — speaker honoraria from: AstraZeneca; Wiktor Kuliczkowski — none; Jacek Legutko — speaker and consultancy honoraria from: AstraZeneca, Bayer; Maciej Lesiak - speaker and consultancy honoraria from: AstraZeneca, Bayer; Jolanta M. Siller-Matula — speaker honoraria from: Chiesi, Bayer, Medtronic, Daiichi Sankyo, BMS; Klaudiusz Nadolny - speaker honoraria from: AstraZeneca; Krzysztof Pstrągowski - none; Salvatore Di Somma - none; Giuseppe Specchia - none; Janina Stępińska — speaker and consultancy honoraria from: AstraZeneca, Bayer, Boehringer Ingelheim, Novartis, Pfizer, Sanofi; Udaya S. Tantry - honoraria from: UptoDate; Agnieszka Tycińska - speaker honorariafrom: Bayer, AstraZeneca, Servier, Krka, Orion Pharma, Fresenius, Fisher \& Paykel; Monica Verdoia - none; Wojciech Wojakowski - speaker honoraria from: AstraZeneca, Pfizer, Boehringer Inhelheim; Eliano P. Navarese - speaker and consultancy honoraria from: AstraZeneca, Abbott, Bayer, Sanofi-Regeneron, Amgen, Pfizer, outside the submitter work; grants from Amgen, Abbott.

\section{References}

1. Neumann FJ, Sousa-Uva M, Ahlsson A, et al. ESC Scientific Document Group. 2018 ESC/EACTS Guidelines on myocardial revascularization. Eur Heart J. 2019; 40(2): 87-165, doi: 10.1093/ eurheartj/ehy394, indexed in Pubmed: 30165437.
2. Myat A, Tantry US, Kubica J, et al. Current controversies in the use of aspirin and ticagrelor for the treatment of thrombotic events. Expert Rev Cardiovasc Ther. 2016; 14(12): 1361-1370, doi: 10.1080/14779072.2016.1247693, indexed in Pubmed: 27740874.

3. Navarese EP, Khan SU, Kołodziejczak M, et al. Comparative Efficacy and Safety of Oral P2Y Inhibitors in Acute Coronary Syndrome: Network Meta-Analysis of 52816 Patients From 12 Randomized Trials. Circulation. 2020; 142(2): 150-160, doi: 10.1161/CIRCULATIONAHA.120.046786, indexed in Pubmed: 32468837.

4. Kubica J, Adamski P, Paciorek P, et al. Treatment of patients with acute coronary syndrome: Recommendations for medical emergency teams: Focus on antiplatelet therapies. Updated experts`s standpoint. Cardiol J. 2018; 25(3): 291-300, doi: 10.5603/ CJ.a2018.0042, indexed in Pubmed: 29671864.

5. Kubica J, Jaguszewski M. ISAR-REACT 5 - What have we learned? Cardiol J. 2019; 26(5): 427-428, doi: 10.5603/ CJ.a2019.0090, indexed in Pubmed: 31536136.

6. Ostrowska M, Kubica J, Adamski P, et al. Stratified Approaches to Antiplatelet Therapies Based on Platelet Reactivity Testing. Front Cardiovasc Med. 2019; 6: 176, doi: 10.3389/ fcvm.2019.00176, indexed in Pubmed: 31850373.

7. Fox KAA, Carruthers KF, Dunbar DR, et al. Underestimated and under-recognized: the late consequences of acute coronary syndrome (GRACE UK-Belgian Study). Eur Heart J. 2010; 31(22): 2755-2764, doi: 10.1093/eurheartj/ehq326, indexed in Pubmed: 20805110.

8. Jernberg T, Hasvold P, Henriksson M, et al. Cardiovascular risk in post-myocardial infarction patients: nationwide real world data demonstrate the importance of a long-term perspective. Eur Heart J. 2015; 36(19): 1163-1170, doi: 10.1093/eurheartj/ehu505, indexed in Pubmed: 25586123.

9. Rapsomaniki E, Thuresson M, Yang E, et al. Using big data from health records from four countries to evaluate chronic disease outcomes: a study in 114364 survivors of myocardial infarction. Eur Heart J Qual Care Clin Outcomes. 2016; 2(3): 172-183, doi: 10.1093/ehjqcco/qcw004, indexed in Pubmed: 29474617.

10. Knuuti J, Wijns W, Saraste A, et al. ESC Scientific Document Group. 2019 ESC Guidelines for the diagnosis and management of chronic coronary syndromes. Eur Heart J. 2020; 41(3): 407-477, doi: 10.1093/eurheartj/ehz425, indexed in Pubmed: 31504439.

11. Collet JP, Thiele H, Barbato E, et al. ESC Scientific Document Group. 2020 ESC Guidelines for the management of acute coronary syndromes in patients presenting without persistent ST-segment elevation. Eur Heart J. 2020 [Epub ahead of print], doi: 10.1093/eurheartj/ehaa575, indexed in Pubmed: 32860058.

12. Kubica J, Adamski P, Buszko K, et al. Platelet inhibition with standard vs. lower maintenance dose of ticagrelor early after myocardial infarction (ELECTRA): a randomized, open-label, active-controlled pharmacodynamic and pharmacokinetic study. Eur Heart J Cardiovasc Pharmacother. 2019; 5(3): 139-148, doi: 10.1093/ehjcvp/pvz004, indexed in Pubmed: 30689800.

13. Kubica J, Adamski P, Buszko K, et al. Rationale and Design of the Effectiveness of LowEr maintenanCe dose of TicagRelor early After myocardial infarction (ELECTRA) pilot study. Eur Heart J Cardiovasc Pharmacother. 2018; 4(3): 152-157, doi: 10.1093/ ehjcvp/pvx032, indexed in Pubmed: 29040445.

14. Mauri L, Kereiakes DJ, Yeh RW, et al. DAPT Study Investigators. Twelve or 30 months of dual antiplatelet therapy after 
drug-eluting stents. N Engl J Med. 2014; 371(23): 2155-2166, doi: 10.1056/NEJMoa1409312, indexed in Pubmed: 25399658.

15. Yeh RW, Kereiakes DJ, Steg PG, et al. DAPT Study Investigators. Benefits and risks of extended duration dual antiplatelet therapy after PCI in patients with and without acute myocardial infarction. J Am Coll Cardiol. 2015; 65(20): 2211-2221, doi: 10.1016/j. jacc.2015.03.003, indexed in Pubmed: 25787199.

16. Garratt KN, Weaver WD, Jenkins RG, et al. Prasugrel plus aspirin beyond 12 months is associated with improved outcomes after TAXUS Liberté paclitaxel-eluting coronary stent placement. Circulation. 2015; 131(1): 62-73, doi: 10.1161/CIRCULATIONAHA.114.013570, indexed in Pubmed: 25400062.

17. Bonaca MP, Bhatt DL, Cohen M, et al. PEGASUS-TIMI 54 Steering Committee and Investigators. Long-term use of ticagrelor in patients with prior myocardial infarction. N Engl J Med. 2015; 372(19): 1791-1800, doi: 10.1056/NEJMoa1500857, indexed in Pubmed: 25773268.

18. Bhatt DL, Bonaca MP, Bansilal S, et al. Reduction in ischemic events with ticagrelor in diabetic patients with prior myocardial infarction in PEGASUS-TIMI 54. J Am Coll Cardiol. 2016; 67(23): 2732-2740, doi: 10.1016/j.jacc.2016.03.529, indexed in Pubmed: 27046160 .

19. Bonaca MP, Bhatt DL, Storey RF, et al. Ticagrelor for prevention of ischemic events after myocardial infarction in patients with peripheral artery disease. J Am Coll Cardiol. 2016; 67(23): 2719-2728, doi: 10.1016/j.jacc.2016.03.524, indexed in Pubmed: 27046162 .

20. Bonaca MP, Bhatt DL, Steg PG, et al. Ischaemic risk and efficacy of ticagrelor in relation to time from P2Y12 inhibitor withdrawal in patients with prior myocardial infarction: insights from PEGASUS-TIMI 54. Eur Heart J. 2016; 37(14): 1133-1142, doi: 10.1093/eurheartj/ehv531, indexed in Pubmed: 26491109.

21. Bansilal S, Bonaca MP, Cornel JH, et al. Ticagrelor for secondary prevention of atherothrombotic events in patients with multivessel coronary disease. J Am Coll Cardiol. 2018; 71(5): 489-496, doi: 10.1016/j.jacc.2017.11.050, indexed in Pubmed: 29406853.

22. Eikelboom J, Connolly S, Bosch J, et al. Rivaroxaban with or without aspirin in stable cardiovascular disease. N Engl J Med. 2017; 377(14): 1319-1330, doi: 10.1056/nejmoa1709118.

23. Adamski P, Adamska U, Ostrowska M, et al. Evaluating current and emerging antithrombotic therapy currently available for the treatment of acute coronary syndrome in geriatric populations. Expert Opin Pharmacother. 2018; 19(13): 1415-1425, doi: 10.1080/14656566.2018.1510487, indexed in Pubmed: 30132731.

24. Boinska J, Koziński M, Kasprzak M, et al. Diurnal variations in tissue factor and tissue factor pathway inhibitor concentrations in relation to on-treatment platelet reactivity: an analysis of patients with acute myocardial infarction. Platelets. 2020; 31(7): 877-883, doi: 10.1080/09537104.2019.1693037, indexed in Pubmed: 31744370.

25. Adamski P, Buszko K, Sikora J, et al. Determinants of high platelet reactivity in patients with acute coronary syndromes treated with ticagrelor. Sci Rep. 2019; 9(1): 3924, doi: 10.1038/s41598019-40628-0, indexed in Pubmed: 30850677.

26. Mauri L, Kereiakes DJ, Normand SLT, et al. Rationale and design of the dual antiplatelet therapy study, a prospective, multicenter, randomized, double-blind trial to assess the effectiveness and safety of 12 versus 30 months of dual antiplatelet therapy in subjects undergoing percutaneous coronary intervention with either drug-eluting stent or bare metal stent placement for the treatment of coronary artery lesions. Am Heart J. 2010; 160(6): 1035-41, 1041.e1, doi: 10.1016/j.ahj.2010.07.038, indexed in Pubmed: 21146655.

27. Li P, Liu JP. Long-term risk of late and very late stent thrombosis in patients treated with everolimus against paclitaxel-eluting stents: an updated meta-analysis. Coron Artery Dis. 2014; 25(5): 369-377, doi: 10.1097/MCA.0000000000000109, indexed in Pubmed: 24818639 .

28. Dangas GD, Serruys PW, Kereiakes DJ, et al. Meta-analysis of everolimus-eluting versus paclitaxel-eluting stents in coronary artery disease: final 3-year results of the SPIRIT clinical trials program (Clinical Evaluation of the Xience V Everolimus Eluting Coronary Stent System in the Treatment of Patients With De Novo Native Coronary Artery Lesions). JACC Cardiovasc Interv. 2013; 6(9): 914-922, doi: 10.1016/j.jcin.2013.05.005, indexed in Pubmed: 24050859 .

29. EMA/CHMP/18297/2016. 17 December 2015. http://www.ema. europa.eu/docs/en_GB/document_library/EPAR_-_Assessment_Report_-_Variation/human/001241/WC500203874.pdf (17 June 2019).

30. Dellborg M, Bonaca MP, Storey RF, et al. Efficacy and safety with ticagrelor in patients with prior myocardial infarction in the approved European label: insights from PEGASUS-TIMI 54. Eur Heart J Cardiovasc Pharmacother. 2019; 5(4): 200-206, doi: 10.1093/ehjcvp/pvz020, indexed in Pubmed: 31218354.

31. Verdoia M, Kedhi E, Suryapranata H, et al. Ticagrelor in the prevention of coronary and non-coronary atherothrombotic events: A comprehensive meta-analysis of 10 randomized trials. Atherosclerosis. 2019; 284: 136-147, doi: 10.1016/j.atherosclerosis.2019.02.011, indexed in Pubmed: 30884417.

32. Furtado RHM, Nicolau JC, Magnani G, et al. Long-term ticagrelor for secondary prevention in patients with prior myocardial infarction and no history of coronary stenting: insights from PEGASUS-TIMI 54. Eur Heart J. 2020; 41(17): 1625-1632, doi: 10.1093/eurheartj/ehz821, indexed in Pubmed: 31811715.

33. Gurbel PA, Fox KAA, Tantry US, et al. Combination Antiplatelet and Oral Anticoagulant Therapy in Patients With Coronary and Peripheral Artery Disease. Circulation. 2019; 139(18): 21702185, doi: 10.1161/CIRCULATIONAHA.118.033580, indexed in Pubmed: 31034291.

34. Mega JL, Braunwald E, Wiviott SD, et al. ATLAS ACS 2-TIMI 51 Investigators. Rivaroxaban in patients with a recent acute coronary syndrome. N Engl J Med. 2012; 366(1): 9-19, doi: 10.1056/ NEJMoa1112277, indexed in Pubmed: 22077192.

35. Connolly S, Eikelboom J, Bosch J, et al. Rivaroxaban with or without aspirin in patients with stable coronary artery disease: an international, randomised, double-blind, placebo-controlled trial. The Lancet. 2018; 391(10117): 205-218, doi: 10.1016/ s0140-6736(17)32458-3.

36. Bhatt DL, Eikelboom JW, Connolly SJ, et al. COMPASS Steering Committee and Investigators. Role of Combination Antiplatelet and Anticoagulation Therapy in Diabetes Mellitus and Cardiovascular Disease: Insights From the COMPASS Trial. Circulation. 2020; 141(23): 1841-1854, doi: 10.1161/CIRCULATIONAHA.120.046448, indexed in Pubmed: 32223318.

37. Steffel J, Eikelboom JW, Anand SS, et al. The COMPASS Trial: Net Clinical Benefit of Low-Dose Rivaroxaban Plus Aspirin as Compared With Aspirin in Patients With Chronic Vascular Disease. Circulation. 2020; 142(1): 40-48, doi: 10.1161/CIRCULATIONAHA.120.046048, indexed in Pubmed: 32436455. 
38. Sharma M, Hart RG, Connolly SJ, et al. Stroke Outcomes in the COMPASS Trial. Circulation. 2019; 139(9): 1134-1145, doi: 10.1161/ CIRCULATIONAHA.118.035864, indexed in Pubmed: 30667279.

39. Bainey KR, Welsh RC, Connolly SJ, et al. COMPASS Investigators. Rivaroxaban Plus Aspirin Versus Aspirin Alone in Patients With Prior Percutaneous Coronary Intervention (COMPASS-PCI). Circulation. 2020; 141(14): 1141-1151, doi: 10.1161/CIRCULATIONAHA.119.044598, indexed in Pubmed: 32178526.

40. Kozinski M, Bielis L, Wisniewska-Szmyt J, et al. Diurnal variation in platelet inhibition by clopidogrel. Platelets. 2011; 22(8): 579-587, doi: 10.3109/09537104.2011.582900, indexed in Pubmed: 21627410.

41. Kubica A, Kozinski M, Grzesk G, et al. Genetic determinants of platelet response to clopidogrel. J Thromb Thrombolysis. 2011; 32(4): 459-466, doi: 10.1007/s11239-011-0611-8, indexed in Pubmed: 21706290.

42. Kubica A, Kasprzak M, Siller-Matula J, et al. Time-related changes in determinants of antiplatelet effect of clopidogrel in patients after myocardial infarction. Eur J Pharmacol. 2014; 742: 47-54, doi: 10.1016/j.ejphar.2014.08.009, indexed in Pubmed: 25199965.

43. Gurbel PA, Tantry US. Do platelet function testing and genotyping improve outcome in patients treated with antithrombotic agents?: platelet function testing and genotyping improve outcome in patients treated with antithrombotic agents. Circulation. 2012; 125(10): 1276-87; discussion 1287, doi: 10.1161/CIRCULATIONAHA.111.031195, indexed in Pubmed: 22412089.

44. Brunetti ND, De Gennaro L, Di Biase M, et al. Prolonged double antiplatelet therapy vs association of antiplatelet and low dose of anticoagulant therapy: PEGASUS or COMPASS? Int J Cardiol Heart Vasc. 2019; 24: 100401, doi: 10.1016/j.ijcha.2019.100401, indexed in Pubmed: 31763434.

45. Capodanno D, Bhatt DL, Eikelboom JW, et al. Dual-pathway inhibition for secondary and tertiary antithrombotic prevention in cardiovascular disease. Nat Rev Cardiol. 2020; 17(4): 242-257, doi: 10.1038/s41569-019-0314-y, indexed in Pubmed: 31953535.

46. Ramacciotti E, Weitz JI. Rivaroxaban plus aspirin for cardiovascular protection: Rationale for the vascular dose and dual pathway inhibition. Thromb Res. 2019; 184: 44-49, doi: 10.1016/j.thromres.2019.09.033, indexed in Pubmed: 31706067.

47. González-Juanatey JR, Almendro-Delia M, Cosín-Sales J, et al. Residual risk reduction opportunities in patients with chronic coronary syndrome. Role of dual pathway inhibition. Expert Rev Clin Pharmacol. 2020; 13(7): 695-706, doi: 10.1080/17512433.2020.1772056, indexed in Pubmed: 32434452 .

48. Kalbacher D, Waldeyer C, Blankenberg S, et al. Beyond conventional secondary prevention in coronary artery disease-what to choose in the era of CANTOS, COMPASS, FOURIER, ODYSSEY and PEGASUS-TIMI 54? A review on contemporary literature. Ann Transl Med. 2018; 6(16): 323, doi: 10.21037/ atm.2018.08.03, indexed in Pubmed: 30364059.

49. Kubica A, Kasprzak M, Obońska K, et al. Discrepancies in assessment of adherence to antiplatelet treatment after myocardial infarction. Pharmacology. 2015; 95(1-2): 50-58, doi: 10.1159/000371392, indexed in Pubmed: 25592409.

50. Kubica A, Obońska K, Kasprzak M, et al. Prediction of high risk of non-adherence to antiplatelet treatment. Kardiol Pol. 2016; 74(1): 61-67, doi: 10.5603/KP.a2015.0117, indexed in Pubmed: 26101025.

51. Kubica A, Obońska K, Fabiszak T, et al. Adherence to antiplatelet treatment with P2Y12 receptor inhibitors. Is there anything we can do to improve it? A systematic review of randomized trials. Curr Med Res Opin. 2016; 32(8): 1441-1451, doi: 10.1080/03007995.2016.1182901, indexed in Pubmed: 27112628.

52. Kosobucka A, Michalski P, Pietrzykowski $€$, et al. The impact of readiness to discharge from hospital on adherence to treatment in patients after myocardial infarction. Cardiol J. 2020 [Epub ahead of print], doi: 10.5603/CJ.a2020.0005, indexed in Pubmed: 32037501.

53. Pietrzykowski $€$, Michalski P, Kosobucka A, et al. Medication adherence and its determinants in patients after myocardial infarction. Sci Rep. 2020; 10(1): 12028, doi: 10.1038/s41598-02068915-1, indexed in Pubmed: 32694522.

54. Kubica A, Bączkowska A. Rationale for motivational interventions as pivotal element of multilevel educational and motivational project (MEDMOTION). Folia Cardiologica. 2020; 15(1): 6-10, doi: 10.5603/FC.2020.0003.

55. Gurbel PA, Tantry US. Deciding about prolonged ticagrelor therapy in coronary clot formers: an ongoing dilemma. Eur Heart J. 2016; 37(14): 1143-1144, doi: 10.1093/eurheartj/ehv573, indexed in Pubmed: 26530109. 